Published in Australian Journal of Botany (2005) 53, 323-335.

\title{
Intra-specific variation in leaf attributes of four savanna tree species across a rainfall gradient in tropical Australia
}

\author{
L. D. Prior ${ }^{1}$, D. M. J. S. Bowman ${ }^{1}$ and D. Eamus ${ }^{2}$
}

Email: lynda.prior@cdu.edu.au

\author{
${ }^{1}$ Key Centre for Tropical Wildlife Management, Charles Darwin University, \\ Darwin, Northern Territory 0909, Australia \\ ${ }^{2}$ Department of Environmental Sciences, University of Technology, Sydney, NSW \\ 2007, Australia
}

\section{Summary}

1. Leaf attributes of four savanna tree species were measured along a rainfall gradient (1650 to $950 \mathrm{~mm}$ per annum) in the Australian monsoon tropics.

2. Leaves sampled at approximately $20 \mathrm{~km}$ intervals along a transect showed that as mean annual rainfall decreased, leaf thickness increased for three of these four species. However, a corresponding decrease in leaf density for two species meant that leaf mass per area increased significantly only for one species.

3. Detailed ecophysiological measurements were made during both the wet and dry seasons near the extremes and middle of this transect. Assimilation per unit mass was similar at all three sites but assimilation per leaf area was higher at the drier sites because leaves were thicker with higher mass per area. These trends probably reflect reduced tree density and leaf area index at the drier sites, which offsets the lower rainfall, thereby allowing similar rates of assimilation per unit carbohydrate invested in leaves.

4. The limited variation in leaf physiological responses of four widespread savanna tree species to a rainfall gradient suggests a genetically fixed 
ensemble of physiological traits that may control the turn-over of species across the rainfall gradient.

Key Words: photosynthesis, specific leaf area, LMA

\section{Introduction}

That the geographic distribution and biomass abundance of plant species systematically changes across precipitation gradients throughout the world is central to all accounts of global vegetation patterns (Schimper 1903). However, the ecophysiological processes that underlie this biogeographic fact are not well understood. Such knowledge is important in the development of global vegetation models designed to predict the consequences of global climate change. A number of correlative studies have shown a range of inter- and intra-specific responses of leaves with decreasing rainfall. For example, leaf mass per area (LMA) increases with decreasing rainfall; this has been demonstrated within species (Castro-Díez et al. 1997) and genera (Cunningham et al. 1999; Lamont et al. 2002), as well as for species assemblage means (Midgley et al. 1995; Wright et al. 2001). Leaves may be narrower, thicker and denser, with more sclerified vasculature (Cunningham et al. 1999). The observed increased foliar nitrogen and phosphorus with increasing aridity in some species (Wright et al. 2001; Lamont et al. 2002; Schulze et al. 1998) contrasts with the generally reported inverse relationship between sclerophylly and foliar $\mathrm{N}$ and $\mathrm{P}$ established for a diversity of taxa (e.g. Loveless 1961; Turner 1994).

The meta-analysis by Niinemets (2001), based on the leaf attributes of 597 species sampled in various biomes, found that as precipitation declined leaf density increased and to a lesser extent so did leaf thickness and LMA. While Niinemets' (2001) study was global in scope, data were lacking for many biomes, with a consequent over-representation of studies conducted in temperate areas. How leaves respond to climatic gradients in the seasonally dry tropics has received little attention. In this biome, conditions for plant growth alternate between a favourable wet season with high temperatures, rainfall and humidity, and an unfavourable dry season with severe soil and atmospheric drought. Recent work in the Australian monsoon tropics has revealed two broad strategies to cope with this physiologically demanding dry season: leaf shedding, where the leaves of deciduous trees tend to have high $\mathrm{A}_{\text {mass }}$, $\mathrm{N}_{\text {mass }}$ and $\mathrm{P}_{\text {mass }}$, and low LMA, or drought tolerance where evergreen species endure 
seasonal drought, are generally sclerophyllous, with low $\mathrm{A}_{\text {mass }}, \mathrm{N}_{\text {mass }}$ and $\mathrm{P}_{\text {mass }}$, and high LMA (Prior et al. 2003).

Clearly more work is required to understand how leaf attributes change across precipitation gradients. The Australian monsoon tropics present a 'model' system to explore how the leaf attributes adjust to increasing aridity both within and between plant species for the following three reasons. First, the absence of mountain ranges has produced a strong relationship between increasing distance from the north coast and total wet season rainfall and the duration and reliability of the rainy season in the region under the influence of the summer monsoon, north of the $500 \mathrm{~mm}$ rainfall isohyet at around $18^{\circ} \mathrm{S}$ (Bowman 1996, 2002; Cook and Heerdegen 2001) (Fig. 1). There are small differences in solar radiation (Roderick et al. 2001) and temperature (Bowman and Connors 1996) along the gradient, but importantly, no major trends in soil fertility because soils are typically derived from deeply weathered silicious parent materials. Second, the major vegetation type under the influence of the monsoon is tropical savanna dominated by evergreen trees in the family Myrtaceae. Within this broad climatic zone, as rainfall decreases there are significant changes in the structure and composition of savanna vegetation. Tree density (Schultze et al. 1998), tree height, tree basal area, tree canopy cover, woody species richness, deciduous species richness (Williams et al. 1996), leaf area index (Hoogerwerf and van Wieringen 2000), understorey evaporation and stand water use (Hutley et al. 2001) all decline as rainfall decreases. Third, there is indirect evidence from that some tree taxa show changes in their ecophysiological performance, with stable carbon isotope studies suggesting that water use efficiency of woody species increases with increasing aridity (Schulze et al. 1998; Miller et al. 2001)

The aim of this study was to systematically assess intra-specific variation in a range of leaf attributes along a $740 \mathrm{~mm}$ rainfall gradient in tropical Australia, using four tree species that are widespread in the region. The study had two components: (a) a survey of two easily-measured leaf attributes (LMA and thickness) at 22 locations along the rainfall gradient, and (b) at the two extremes and middle of this transect, detailed physiological measurements of a range of leaf attributes and tree growth rates along with estimates of stand basal area and canopy cover.

\section{Materials and methods}




\section{STUDY SPECIES}

The four tree species selected for study are very widespread across northern Australia and characteristic of tropical eucalypt savannas on deep, well drained soils. Eucalyptus tetrodonta F. Muell. (Myrtaceae) is a tall (10-30 m high) evergreen tree that dominates large areas of Australian savanna (Fensham and Kirkpatrick 1992; Brock 1993). Erythrophleum chlorostachys F. Muell. (Caesalpiniaceae) is a subordinate savanna canopy tree (12-18 $\mathrm{m}$ high) that at the end of the dry season replaces its canopy in a synchronised shedding of old and flushing of new leaves (Prior et al. submitted) (The generic name is given in full throughout the paper to avoid confusion with Eucalyptus). Buchanania obovata Engl. (Anacardiaceae) is a small, facultatively deciduous tree or shrub (1 to $10 \mathrm{~m}$ high) common in the understorey of savanna. Planchonia careya F. Muell. (Lecythidaceae) is a small, fully deciduous tree or shrub (1 to $8 \mathrm{~m}$ high).

\section{LEAF THICKNESS AND LMA ALONG THE TRANSECT}

The four species were systematically sampled along a $360 \mathrm{~km}$ section of the Stuart highway between $12.37^{\circ} \mathrm{S}$ and $14.65^{\circ} \mathrm{S}$ (Fig. 1) in April 2002, when most leaves were recently mature. Starting from the city of Darwin, the highway was divided into consecutive $20 \mathrm{~km}$ sections, from which the four species were sampled if present; not all species occurred on each section. Leaves were also collected from the three physiological study sites described below. Each sample location was recorded using a Global Positioning System. At each location, a total of 18 mature, healthy leaves from 3-6 trees of each available species was removed and stored in sealed bags under refrigeration. Thickness of each leaf was measured on either side of the mid-vein within 3 days of harvest. LMA of these leaves was then determined by punching 4 discs from each leaf (area per disc was $30 \mathrm{~mm}^{2}$ ) and weighing the dried discs. Leaf density was calculated as LMA divided by leaf thickness. Regression analysis was used to measure the strength of the relationship between these variables and predicted mean annual rainfall. We used the long term records (49 to 128 years) available from the Commonwealth Bureau of Meteorology (2003) for 8 sites between Darwin and Alice Springs to derive the following equation: 
Rainfall $(\mathrm{mm})=1621-67016 /$ Latitude $+841649 *(\text { Latitude })^{2} \quad \mathrm{R}^{2}=0.994$

where Latitude is expressed as ${ }^{\circ} \mathrm{S}$.

\section{STUDY SITES FOR PHYSIOLOGICAL MEASUREMENTS}

Three study sites were established near the wet (Site 1) and dry (Site 3) extremes and the middle (Site 2) of the transect. Site 1 was located at the Territory Wildlife Park, in the open forest site described by Prior et al. (2003). Site 2 was adjacent to the abandoned World War II McDonald airstrip $15 \mathrm{~km}$ north-west of Pine Creek. Site 3 was at Cutta Cutta Caves Nature Park, 27 km south-east of Katherine. Site characteristics are listed in Table 1. The sites were all located in open forest or woodland dominated by the widespread Eucalyptus tetrodonta (classed as Broad Vegetation Group 5 by Fox et al. 2001) on silicious soils. The sites were selected to be relatively secure from wildfire but despite this, Site 2 was burnt before dry season measurements were made.

Rainfall records for the 2001/02 wet season during the study period were compiled from meteorological stations nearest the three study sites (Figs $1 \& 2$ ). Basic data on the soils and vegetation of the sites the following measurement were collected to enable comparisons amongst the sites. Volumetric soil water content was measured using time domain reflectometry (ThetaProbe soil moisture sensors, DeltaT Devices LTD, Cambridge, UK.) Two sensors were installed at $0.5 \mathrm{~m}$ depth at each site. Sensor output was measured monthly with a multimeter (RadioShack, China). Soil samples were collected at each of the sites soils at $0.2 \mathrm{~m}$ depth from four profiles and the following measurements were made. Gravel content $(>2 \mathrm{~mm})$ was determined by sieving and the texture of the $<2 \mathrm{~mm}$ fraction was qualitatively estimated by feel (Brady \& Weil 1999). Total Kjeldahl nitrogen and phosphorus were determined using flow injection analysis (Lachat Instruments, WI, USA) of the $<1$ $\mathrm{mm}$ soil fraction that had been dried to constant weight at $60{ }^{\circ} \mathrm{C}$. Stand basal area and stem density were measured on 4 quadrats (each $20 \mathrm{~m}$ by $20 \mathrm{~m}$ ) per site.

Diameter at breast height was measured for all stems taller than $1.5 \mathrm{~m}$. Percentage canopy cover was measured at 10 random locations within each site with a densiometer (Model A, Forest Densiometers, Oklahoma, USA) in March 2002, when leaf area was at its yearly maximum, and again in August 2002, near its annual minimum. 


\section{STEM GROWTH AND LEAF PHENOLOGY}

Six to twelve trees of each of the study species, at least $2 \mathrm{~m}$ tall and covering the size range present, were chosen for growth measurements at each site. Diameter at breast height (DBH) was measured every three months during the study period (August 2001 to August 2002). No DBH measurements were made at Site 2 in August 2002 because the site had been burnt. Leaf phenology was observed monthly.

\section{LEAF ATTRIBUTES}

At each site, leaf attributes were measured on six trees of each species. Eighteen leaves per species (3 leaves per tree) were measured in the wet season (December 2001 and January 2002). Another 18 leaves from the same trees were measured in the mid-dry season (July 2002), except at Site 2, which had been burnt. Here, dry season measurements were made on substitute trees at a similar site about $500 \mathrm{~m}$ away. At all sites only E. tetrodonta and Erythrophleum chlorostachys had leaves suitable for dry season measurements.

Assimilation and transpiration measurements were made on well-lit leaves between 0.5 and $2.5 \mathrm{~m}$ high, as described by Prior et al. (2003). Fully expanded and thickened leaves were used for these physiological measurements. Wet season measurements used leaves that had recently matured, whereas leaves used in the dry season were generally older. We used mid-dry rather than late-dry season measurements because few leaves remain in reasonable condition late in the dry season. Assimilation per unit area, $\mathrm{A}_{\text {area }}$, was measured under light-saturating conditions (photon flux density $>1200 \mu \mathrm{mol} \mathrm{m}^{-2} \mathrm{~s}^{-1}$ ) with a portable photosynthesis system (LiCor Li 6200, Lincoln, Nebraska). Measurements were made in the morning, when assimilation rates are highest (Prior et al. 1997a, b). Leaves were then immediately sealed in plastic bags containing damp paper toweling before being fully rehydrated in the laboratory. Saturated mass of the lamina was measured the next day so that saturated water content could be calculated. Leaf thickness was measured in four places between major veins with a micrometer (Moore and Wright, Sheffield, U.K.). Foliar chlorophyll content was then measured (wet season only) using a chlorophyll meter (SPAD-502, Minolta, Osaka, Japan). The chlorophyll meter was 
calibrated for each species individually using the extraction method of Coombs et al. (1985). Area of each leaf was then measured using a Delta-T Scan image analysis system (Delta-T Devices, Cambridge, UK). Dry mass was determined after leaves were dried for a minimum of 48 hours at $70^{\circ} \mathrm{C}$. Leaf density was calculated as leaf mass per area (LMA) divided by leaf thickness.

For the wet season samples only, total Kjeldahl nitrogen and phosphorus were determined using flow injection analysis (Lachat Instruments, Milwaukee, Wisconsin). The three leaves from each tree were pooled, mid-veins were excised, and the remaining leaf was ground to a powder, and a sample digested in hot, concentrated sulphuric acid before being subjected to the micro-Kjeldahl procedure.

\section{STATISTICAL ANALYSES}

Analysis of variance (ANOVA) was used to determine significance of differences between site characteristics and leaf attributes. Log and square root transformations were used as appropriate. Repeated measures ANOVA of $\log (\mathrm{x}+1)$-transformed quarterly DBH increments was used to analyse growth data. The May to August data was excluded from some analyses because Site 2 trees were burnt during this time, but growth during this quarter contributed very little to the annual total at the other two sites.

\section{Results}

\section{LEAF THICKNESS AND LMA ALONG THE TRANSECT}

Leaves of B. obovata, Erythrophleum chlorostachys, E. tetrodonta and P. careya were sampled at 16, 18, 13 and 14 locations respectively because of variation in the distribution and abundance of these species. Leaves become thicker with decreasing rainfall for the three species Erythrophleum chlorostachys, E. tetrodonta and $P$. careya (Fig. 3). However, LMA increased significantly with decreasing rainfall only for Erythrophleum chlorostachys because of an apparent decrease in leaf density in $E$. tetrodonta and $P$. careya. For all species combined there was no overall trend of LMA with mean annual rainfall. 


\section{RAINFALL AND SOIL MOISTURE AT THE STUDY SITES}

Near the north coast, rainfall was much lower than the average although the length of the wet season was typical (Fig. 2). By contrast, wet season length inland was shorter than average, yet both Pine Creek and Cutta Cutta meteorological stations recorded above-average rainfall due to an exceptionally heavy rainfall event in February associated with a intense tropical low pressure system that crossed the Northern Territory around the latitude of the Site 2, but which also brought rain to the other sites (Fig. 2).

Absolute volumetric water content at the three sites reflected soil physical properties such as texture and gravel content (Fig. $4 \&$ Table 1). Water content was lowest at Site 2 where gravel made up of around 50\% and highest at Site 3 which had least gravel context and highest clay content, markedly so at $0.5 \mathrm{~m}$, where soil moisture probes were located. In can be assumed the soils at each site were at field capacity in February because of the heavy rainfall that fell in that month (Fig. 2). The timing of water depletion was similar for all sites, with virtually no water available at $0.5 \mathrm{~m}$ depth after May (Fig. 4). Total soil Kjeldahl nitrogen and phosphorus levels were very low at all three sites with the highest recorded at Site 1 (Table 1).

\section{STEM GROWTH AND LEAF PHENOLOGY}

Total stem density, stand basal area and canopy cover were all much higher at the Site 1 than at the other two sites (Table 1). The proportion of stand basal area made up by E. tetrodonta was much higher at Site $1(82 \%)$ and Site $2(74 \%)$ than at Site $3(26 \%)$. By contrast, $P$. careya and B. obovata each comprised $<0.5 \%$ of stand basal area at Site 1 , but $3-10 \%$ at Sites 2 and 3.

Stem growth, as measured by DBH increments, was extremely seasonal for the four species with most growth occurring in the wet season and with slight shrinkage in the dry season (Fig. 5). Annual stem growth was significantly larger in Erythrophleum chlorostachys than in the other species (Fig. 5). Growth was largest at Site 3 and smallest at Site 1. Species by site interactions were not significant.

The patterns of leaf loss and replacement varied amongst both the species and the sites. The evergreen E. tetrodonta produced new shoots through most of the year 
with major leaf production occurring between September and January at all sites (Fig. 6). New leaf production by Erythrophleum chlorostachys was synchronised within sites but staggered across the rainfall gradient with peak flushing occurring between September and October for Site 1, September and November for Site 2 and February and April for Site 3. Leaf production in B. obovata was very variable between sites. Leaf flush in the deciduous $P$. careya was maximal between September and December at all sites.

\section{LEAF ATTRIBUTES AT THE THREE STUDY SITES}

In general the trends in LMA and leaf thickness were consistent between the transect study and the three study sites. Both studies showed that leaves were thicker on average at the drier sites and B. obovata and E. tetrodonta had the thickest leaves and the largest LMA. Unlike the decrease in leaf density with increasing aridity observed on the transect, the two inland study sites had denser leaves, so that LMA was significantly larger at the drier sites for E. tetrodonta as well as Erythrophleum chlorostachys (Fig. $7 \&$ Table 2).

Because LMA varied across the rainfall gradient, patterns in other leaf attributes varied according to whether variables were expressed on a leaf mass or leaf area basis. Wet season $\mathrm{A}_{\text {mass }}$ was highest for P. careya followed by Erythrophleum chlorostachys with little variation between the three sites (Fig. 7). Interestingly, differences between sites in $\mathrm{A}_{\text {mass }}$ were not significant overall during the wet season, although there was a tendency for $\mathrm{A}_{\text {mass }}$ to increase between the moist and the arid sites in B. obovata. For both species measured in the dry season (Erythrophleum chlorostachys and E. tetrodonta), $\mathrm{A}_{\text {mass }}$ was significantly lower during the dry than the wet seasons, with a larger proportional decrease at Site 1 (52\%) and Site $2(44 \%)$ than at the drier Site $3(27 \%)$. Thus during the dry season, $\mathrm{A}_{\text {mass }}$ increased from the moist to the arid sites (Fig. 7).

Foliar saturated moisture content in the wet season was significantly lower in Erythrophleum chlorostachys than in the other species, and only E. tetrodonta showed a significant decline in this attribute down the moisture gradient. Foliar saturated moisture content declined between the wet and dry season in both Erythrophleum chlorostachys and E. tetrodonta. 
Foliar $\mathrm{N}_{\text {mass }}$ was highest in Erythrophleum chlorostachys and lowest in E. tetrodonta, whereas $\mathrm{P}_{\text {mass }}$ was highest in P. careya and lowest in E. tetrodonta (Fig. 8). Site 1 had the highest foliar $\mathrm{N}_{\text {mass }}$, and together with Site 3, also had higher $\mathrm{P}_{\text {mass }}$ than did Site 2.

On a leaf area basis, there were significant increases in assimilation between the moist and the arid sites, especially in the dry season, that generally reflected higher stomatal conductance at the two more arid sites (Fig. 7). Decreases in $\mathrm{A}_{\text {area }}$ between the wet and the dry seasons ranged from $40 \%$ at Site 1 to $22 \%$ at Site 3 for $E$. tetrodonta and Erythrophleum chlorostachys, while stomatal conductance decreased by $62 \%$ and $41 \%$ respectively. Thus instantaneous transpiration efficiency (the ratio $\mathrm{A}_{\text {area }}$ /stomatal conductance) was higher in the dry than the wet season, and, especially in the dry season, was higher at Sites 2 and 3 (about $\left.32 \times 10^{-6}\right)$ than at Site $1\left(27 \times 10^{-}\right.$ $\left.{ }^{6}\right)$. Differences in assimilation and nutrient content check!!!! between species were smaller on an area than on a mass basis (Fig. 7), while foliar N and P levels were very similar between the three sites when expressed on an area basis. check!!!!

\section{Discussion}

This study provides insights into contrasting adaptations of savanna trees to a rainfall gradient in the monsoon tropics. A significant and unexpected finding is that for the four species studied there was only minor variation in leaf physiological responses across the rainfall gradient. For example, $A_{\text {mass }}$, which represents return on carbon invested in leaves (e.g. Lusk et al. 2003), was very similar at all three sites in the wet season, and, surprisingly, during the dry season was highest at the most arid site. Instantaneous transpiration efficiency was highest at Sites 2 and 3, obviously advantageous at these drier sites. The most conspicuous leaf phenotypic responses were changes in leaf area and thickness and shifts in the schedule of leaf phenology. However minor adjustments in leaf phenology were unrelated to timing of stem growth, which was restricted to the wet season even in species that retained leaves through all or most of the dry season (E. tetrodonta and Erythrophleum chlorostachys). Photosynthate produced during the dry season is presumably stored underground in lignotubers or the root system of these trees.

The larger LMA at Sites 2 and 3 explains why wet season $A_{\text {area }}$ substantially increased down the rainfall gradient despite little variation in $\mathrm{A}_{\text {mass. }}$. The wet season measurements are comparable amongst the sites because all the soils were at field 
capacity in February, as is the case for a typical wet season (Fig. 4). It is unlikely the larger $\mathrm{A}_{\text {area }}$ in the dry season at the more arid sites can be explained by the atypical rainfall pattern in the 2001/02 wet season because Site 1 had approximately $200 \mathrm{~mm}$ in March and April yet there was little rain after that at Sites 2 and 3 (Fig. 2). In this context it is important to, We argue it is more probable that decreased tree density and leaf area index at the drier sites allow similar $\mathrm{A}_{\text {mass }}$ by compensating the lower rainfall and shorter wet season. Since tree water use between Darwin and Katherine is linearly correlated with basal area (Hutley et al. 2001; Cook et al. 2002), competition between trees for water would be most intense at Site 1 given the very high stand basal area here (Table 1). This could lead to the lower $\mathrm{g}_{\mathrm{s}}$ and $\mathrm{A}_{\text {area }}$ observed at the moist site (Site 1) relative to the drier Sites 2 and 3, especially in the dry season.

An alternative interpretation of our results is that they were confounded by the effects of soil type or fire history. It seems unlikely soils can account for the observed trends across the rainfall gradient because of the similarity in $\mathrm{N}_{\text {mass }}$ and $\mathrm{P}_{\text {mass }}$ in the foliage of each species at each site. Furthermore stem increment per tree for each species was largest at the driest site (Site 3) despite having less fertile soil than the wettest site (Site 1). Differences in the rate of surface soil moisture depletion associated with the length and distribution of rainfall during the wet season probably led to the observed differences in timing of leaf flush and leaf fall (Fig. 6). Differences in the leaf phenophases may have influenced our finding of the importance of leaf thickness in responding to the moisture gradient rather than LMA or leaf density. Leaf thickness changes little once a leaf matures while leaf density and LMA continue to increase with age and are more sensitive to when they were sampled (Table 2, this paper, and Prior et al. submitted, Fig. 3). It must also be acknowledged that leaf phenology is also strongly influenced by landscape fire. Early dry season fires may cause evergreen and semi-deciduous trees to flush earlier in the dry season (July) than they normally would (September-October), although peak leaf flushing in the dominant eucalypts and Erythrophleum chlorostachys occurred at the same time regardless of whether or when burning took place (Williams et al. 2003). It is likely that early dry season fires along the Stuart Highway affect timing of subsequent leaf flushes, which led to variability in our measurements of LMA and its components on the roadside transect accounting for some inconsistencies between the transect study and the three ecophysiological sites. 
Inter-specific variation in the response of leaves to rainfall gradients was reported by Castro-Díez et al. (1997), who showed that leaf thickness and LMA increased with declining annual rainfall in Quercus ilex, an evergreen tree while no such response was found for $Q$. coccifera, an evergreen shrub, or $Q$. faginea, a deciduous tree. In our study also, leaf thickness and LMA of the fully deciduous $P$. careya and the semi-deciduous $B$. obovata were relatively unaffected by declining rainfall while the semi-deciduous Erythrophleum chlorostachys and the evergreen $E$. tetrodonta generally showed increases in these leaf attributes. Perhaps by shedding their leaves, deciduous species largely avoid the need to modify them in response to increasing aridity. Castro-Díez et al. (1997) also found that one of the three species (Q. coccifera) studied showed a positive relationship between leaf density and precipitation, as did two species in our study. These trends in leaf density are counter to those found by Niinemets (2001) in his global meta-analysis, again suggesting that the phenotypic response of leaf density to average rainfall within species differs from that between the genetically fixed response of different species.

We suggest that each of the four species has very specific requirements for plant available water because of limited physiological adaptability. The differences within an individual species both along the precipitation gradient are small relative to the differences between the different taxa. Indeed, the individual species tolerance to variation in moisture supply appears to be under strong genetic control because of the limited variation in most leaf attributes. It is therefore possible that phenotypic plasticity, such as changing leaf thickness, determines the geographical range of the individual taxa at the local and regional scale. This interpretation is consistent with the observed gradual turn-over of individual species along the rainfall gradient at the macro-scale and the observed abrupt turnover of species in response to steep edaphic gradients at the local scale (Fensham and Kirkpatrick 1992; Williams et al. 1996). This study therefore provides an ecophysiological explanation for the paradox of geographically widespread tree species that have highly specific edaphic tolerances (Fensham and Kirkpatrick 1992).

Reductions in total tree basal area and \% canopy, which combined with reduced understorey water use (Hutley et al. 2001) shielded leaves from the effects of decreased rainfall until the capacity for phenotypic adjustment of foliar physiology is exceeded. It is therefore possible that the observed turn-over of species across the rainfall gradient is a direct consequence of the balance between assimilation rate and 
consequent whole plant growth against the cost of carbohydrate invested in leaves that have such limited phenotypic flexibility.

\section{Acknowledgements}

We thank staff of the Northern Territory Department of Infrastructure, Planning and Environment for allowing us access to the Territory Wildlife Park and Cutta Cutta Nature Park for this study. Mr Garry Hamilton of Equest Pty Ltd kindly permitted us to use the McDonald Airstrip site. We also thank the Bureau of Meteorology for supplying rainfall data for the study sites. We are grateful to Ms Françoise Foti for careful leaf nutrient analyses. This work was funded by Australian research Council Large Grant A00001382. 


\section{References}

Aldrick, J.M. and Robinson, C.S. (1970). Report on the Land Units of the Katherine-

Douglas area. Department of Lands, Planning and Environment.

Anon. (2000). Cutta Cutta Caves Nature Park Plan of Management. Parks and

Wildlife Commission of the Northern Territory. 41 pp. available at http://www.nt.gov.au/ipe/paw/parks/cuttacuttapom.pdf

Bowman, D.M.J.S. (1996) Diversity patterns of woody species on a latitudinal transect from the monsoon tropics to desert in the Northern Territory, Australia. Australian Journal of Botany 44, 571-580.

Bowman, D.M.J.S. (2002) The Australian summer monsoon: a biogeographic perspective. Australian Geographical Studies 40, 261-277.

Bowman, D.M.J.S. \& Connors (1996) Does low temperature cause the dominance of Acacia on the central Australian mountains? Evidence from a latitudinal gradient from $11^{\circ}$ to $26^{\circ}$ South in the Northern Territory, Australia. Journal of Biogeography 23, 245-256.

Brady, N.C., \& Weil, R.R. (1999). The Nature and Properties of Soils. Prentice Hall, New Jersey, USA.

Brock, J. (1993) Native Plants of Northern Australia. Reed, Chatswood, NSW, Australia.

Castro-Díez, P., Villar-Salvador, P, Pérez-Rontomé, C., Maestro-Martínez, M. \& MontserratMartí, G. (1997) Leaf morphology and leaf chemical composition in three Quercus (Fagaceae) species along a rainfall gradient in NE Spain. Trees 11, 127-134.

Commonwealth Bureau of Meteorology, Australia (2003) http://www.bom.gov.au

Cook, G.D., Williams, R.J., Hutley, L.B., O’Grady, A.P. \& Liedloff, A.C. (2002) Variation in vegetative water use in the savannas of the North Australian Tropical Transect. Journal of Vegetation Science 13, 413-418.

Coombs, J., Hind, G., Leegood, R.C., Tieszen, L.L. \& Vonshak, A. (1985) Analytical Techniques. Techniques in Bioproductivity and Photosynthesis (eds J. Coombs, D. O.Hall, S. P. Long \& J. M. O. Scurlock), pp. 223-224. Pergamon Press, Oxford, U.K.

Cunningham, S.A., Summerhayes, B. \& Westoby, M. (1999) Evolutionary divergences in leaf structure and chemistry, comparing rainfall and nutrient gradients. Ecology 69, 569-588.

Fensham, R.J. \& Kirkpatrick, J.B. (1992). Soil characteristics and tree species distribution in the savannah of Melville Island, Northern Territory. Australian Journal of Botany 40, 311333. 
Fox, I.D., Neldner, V.J., Wilson, G.W. \& Bannink, P.J. (2001) The Vegetation of the Australian Tropical Savannas. Environmental Protection Agency, Brisbane.

Hoogerwerf, C.G., Wieringen, S.M. van (1999). Leaf area index of the savannas of northern Australia. BSc thesis, Department of Terrestrial Ecology, Agricultural University of Wageningen, The Netherlands, and CSIRO Wildlife and Ecology, Darwin.

Hutley, L.B., O’Grady, A.P \& Eamus, D. (2001). Monsoonal influences on evapotranspiration of savanna vegetation of northern Australia. Oecologia 126, 434-443.

Lamont, B.B., Groom, P.K. \& Cowling, R.M. (2002) High leaf mass per area of related species assemblages may reflect low rainfall and carbon isotope discrimination rather than low phosphorus and nitrogen concentrations. Functional Ecology 16, 403-412.

Loveless, A.R. (1961). A nutritional interpretation of sclerophylly based on differences in the chemical composition of sclerophyllous and mesophytic leaves. Annals of Botany NS 25, 168-184.

Lusk, C.H., Wright, I. \& Reich, P.B. (2003). Photosynthetic differences contribute to competitive advantage of evergreen angiosperm trees over evergreen conifers in productive habitats. New Phytologist 160, 329-336.

Midgley, J.J., Van Wyk, G.R. \& Everard, D.A. (1995) Leaf attributes of South African forest species. African Journal of Ecology 33, 160-168.

Miller, J.M., Williams, R.J. \& Farquhar, G.D. (2001) Carbon isotope discrimination by a sequence of Eucalyptus species along a subcontinental rainfall gradient in Australia. Functional Ecology 15, 222-232.

Niinemets, Ü. (2001) Global-scale climatic controls of leaf dry mass per area, density, and thickness in trees and shrubs. Ecology 82, 453-469.

Prior, L.D., Bowman, D.M.J.S. \& Eamus, D. (submitted) Seasonal differences in leaf attributes in Australian tropical tree species: family and habitat comparisons. Submitted to Functional Ecology .

Prior, L.D., Eamus, D. \& Bowman, D.M.J.S. (2003) Leaf attributes in the seasonally dry tropics - a comparison of four habitats in northern Australia. Functional Ecology 17, 504515.

Prior, L.D., Eamus, D. \& Bowman, D.M.J.S. (in press) Tree growth rates in north Australian savanna habitats: seasonal patterns and correlations with leaf attributes. Australian Journal of Botany. 
Prior, L.D., Eamus, D. \& Duff, G.A. (1997a) Seasonal and diurnal patterns of carbon assimilation, stomatal conductance and leaf water potential in Eucalyptus tetrodonta saplings in a wet-dry savanna in Northern Australia. Australian Journal of Botany 45, 241258.

Prior, L.D., Eamus, D. \& Duff, G.A. (1997b) Seasonal trends in carbon assimilation, stomatal conductance, pre-dawn leaf water potential and growth in Terminalia ferdinandiana, a deciduous tree of northern Australian savannas. Australian Journal of Botany 45, 53-69.

Roderick, M.L., Farquhar, G.D., Berry, S.L. \& Noble, I.R. (2001) On the direct effect of clouds and atmospheric particles on the productivity and structure of vegetation. Oecologia 129, 21-30.

Turner, I.M. (1994) A quantitative analysis of leaf form in woody plants from the world's major broadleaved forest types. Journal of Biogeograpy 21, 413-419.

Schimper, A.F.W. (1903). Plant-geography upon a Physiological Basis (translated by W.R. Fisher, revised and edited by P. Groom and I.B. Balfour). Oxford University Press: Oxford.

Schulze, E.-D., Williams, R.J., Farquhar, G.D., Schulze, W., Langridge, J., Miller, J.M. \& Walker, B.H. (1998) Aust. J. Plant Physiol. 25, 413-425.

Sivertsen, D.P., McLeod, P.J. \& Henderson, R.L. (1980) Land Resources of the Berry Springs Nature Park and Proposed Development Area. Land Conservation Unit Report 80/5, Conservation Commission N.T., Darwin, Australia.

Williams, R.J., Duff, G.A., Bowman, D.M.J.S. \& Cook, G.D. (1996). Variation in the composition and structure of tropical savannas as a function of rainfall and soil texture along a large-scale climatic gradient in the Northern Territory, Australia. Journal of Biogeography 23, 747-756.

Williams, R.J., Müller, W.J., Wahren, C.-H., Setterfield, S.A. \& Cusack, J. (2003) Vegetation. In Fire in Tropical Savannas: The Kapalga Experiment. Eds A.N. Andersen, G.D. Cook \& R.J. Williams. Springer-Verlag, New York.

Wright, I.J., Reich, P.B. \& Westoby, M. (2001) Strategy shifts in leaf physiology, structure and nutrient content between species of high- and low-rainfall and high- and low-nutrient habitats. Functional Ecology 15, 423-434. 
Table 1. Characteristics of the three study sites. Soil was sampled from $0.2 \mathrm{~m}$ depth.

\begin{tabular}{|c|c|c|c|c|}
\hline & & Site 1 & Site 2 & Site 3 \\
\hline Location & & $\begin{array}{l}\text { Territory } \\
\text { Wildlife Park }\end{array}$ & $\begin{array}{l}\text { McDonald } \\
\text { Airstrip }\end{array}$ & $\begin{array}{l}\text { Cutta Cutta } \\
\text { Caves Nature } \\
\text { Park }\end{array}$ \\
\hline Latitude & decimal ${ }^{\circ} \mathrm{S}$ & 12.71 & 13.75 & 14.57 \\
\hline $\begin{array}{l}\text { Rainfall - } \\
\text { annual } \\
\text { modelled }\end{array}$ & $\mathrm{mm}$ & 1558 & 1199 & 986 \\
\hline Soil texture & & sandy loam & loamy sand & loamy sand \\
\hline Gravel & $\% \mathrm{w} / \mathrm{w}$ & $0.18 \pm 0.05^{\mathrm{a}}$ & $49.5 \pm 1.7^{b}$ & $0.06 \pm 0.03^{\mathrm{a}}$ \\
\hline $\begin{array}{l}\text { Total Kjeldahl } \\
\text { Nitrogen }\end{array}$ & $\mathrm{mg} \mathrm{g}^{-1}$ & $0.69 \pm 0.13^{\mathrm{a}}$ & $0.22 \pm 0.02^{b}$ & $0.22 \pm 0.04^{b}$ \\
\hline $\begin{array}{l}\text { Total Kjeldahl } \\
\text { Phosphorus }\end{array}$ & $\mathrm{mg} \mathrm{g}^{-1}$ & $0.105 \pm 0.006^{\mathrm{a}}$ & $0.080 \pm 0.004^{b}$ & $0.063 \pm 0.008^{b}$ \\
\hline Basal area & $\mathrm{m}^{2} \mathrm{ha}^{-1}$ & $17.4 \pm 2.2^{\mathrm{a}}$ & $3.5 \pm 0.5^{\mathrm{c}}$ & $6.7 \pm 0.8^{b}$ \\
\hline Stem density & $\mathrm{ha}^{-1}$ & $2881 \pm 204^{\mathrm{a}}$ & $537 \pm 46^{\mathrm{c}}$ & $800 \pm 71^{c}$ \\
\hline $\begin{array}{l}\text { Canopy density } \\
\text { - wet season }\end{array}$ & $\%$ & $47 \pm 3^{\mathrm{a}}$ & $28 \pm 3^{b c}$ & $29 \pm 3^{b c}$ \\
\hline $\begin{array}{l}\text { Canopy density } \\
\text {-dry season }\end{array}$ & $\%$ & $39 \pm 2^{\mathrm{ab}}$ & (burnt) & $22 \pm 3^{c}$ \\
\hline $\begin{array}{l}\text { References to } \\
\text { soil types }\end{array}$ & & $\begin{array}{l}\text { Sivertsen et al. } \\
1980\end{array}$ & $\begin{array}{l}\text { Aldrick and } \\
\text { Robinson } 1970\end{array}$ & $\begin{array}{l}\text { Aldrick and } \\
\text { Robinson } 1970\end{array}$ \\
\hline $\begin{array}{l}\text { References to } \\
\text { vegetation types }\end{array}$ & & $\begin{array}{l}\text { Sivertsen et al. } \\
\text { (1980) } \\
\text { Bowman and } \\
\text { Minchin (1987) } \\
\text { Prior et al. } \\
\text { (2003, } \\
\text { submitted, in } \\
\text { press), }\end{array}$ & & Anon. (2000) \\
\hline
\end{tabular}


Table 2. Summary of results of ANOVAs to determine the significance of differences among species (Sp), sites and seasons (Seas) for (i) all species during the wet season and (ii) wet and dry seasons (repeated measures ANOVA) for Erythrophleum chlorostachys and E. tetrodonta, the only species measured during the dry season. Chlorophyll, $\mathrm{N}_{\text {mass }}$ and $\mathrm{P}_{\text {mass }}$ were only measured during the wet season. * indicates $P<0.05$, ** $<0.01$, $* * *<0.001$, and NS, not significant $(P>0.05)$.

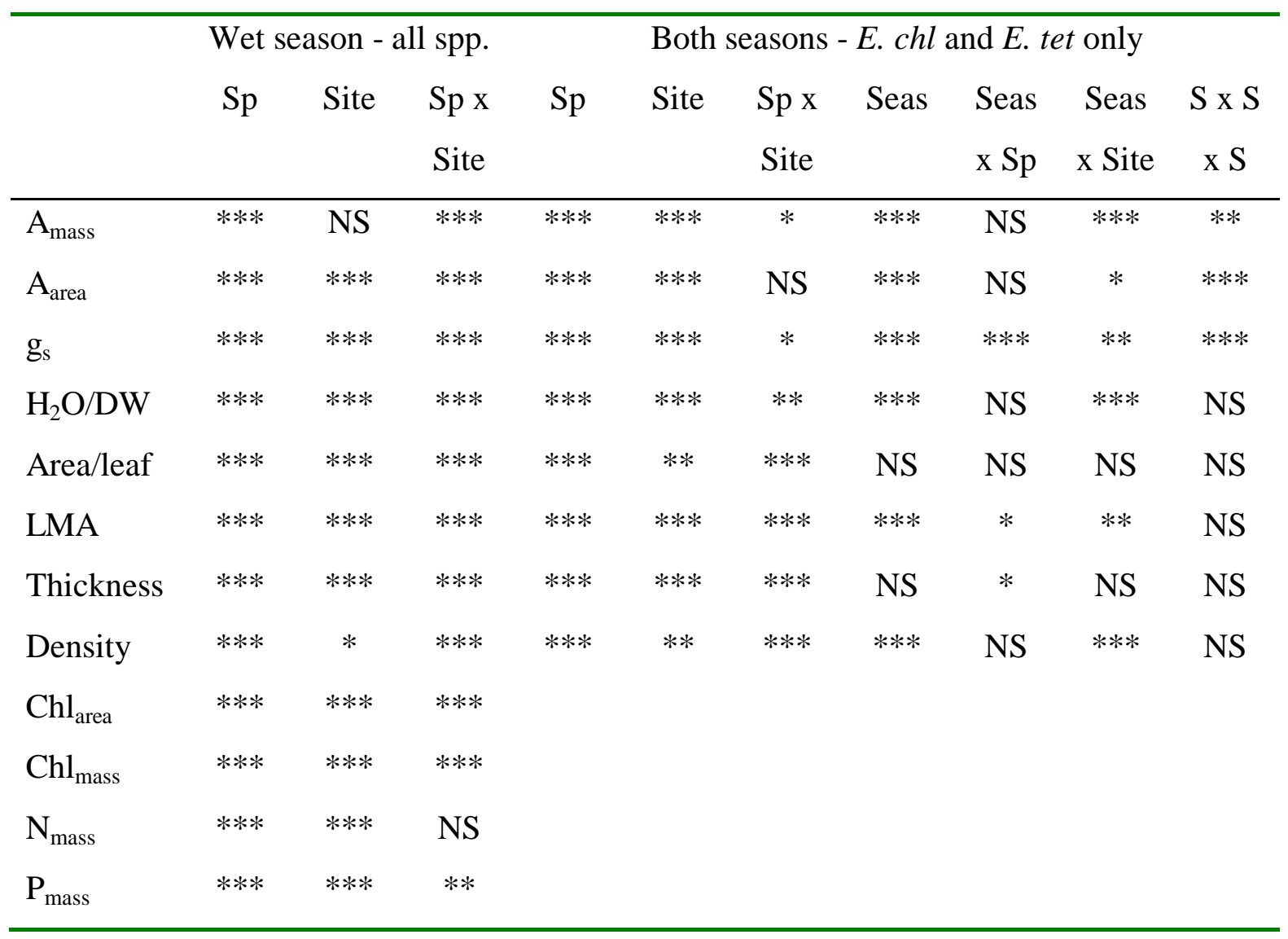




\section{Captions for Figures}

Fig. 1 Australia's Northern Territory north of $18^{\circ} \mathrm{S}$, showing the locations of major towns and transect sample points (solid circles) along the Stuart Highway, and the three ecophysiological study sites (triangles). Isohyets show mm mean annual rainfall, and areas above $400 \mathrm{~m}$ elevation are also indicated.

Fig. 2. Long term mean monthly rainfall and, where available, maximum (solid circles) and minimum temperatures (open circles) for Darwin (near Site 1), Pine Creek (near Site 2) and Katherine (near Site). Actual monthly rainfall at recording stations nearest the study sites during the experimental period is shown in the right hand graphs. (The nearest station to Site 2 is at Pine Creek.) Corresponding annual rainfall is shown at bottom right of each graph. Annual rainfall at Sites 2 and 3 was higher than average, whereas that at Site 1 was lower than average. Note the record February rainfall that fell at Pine Creek in 2002.

Fig. 3. Leaf mass per area, leaf thickness and leaf density plotted against mean annual rainfall for B. obovata (open triangle), Erythrophleum chlorostachys (closed circle), E. tetrodonta (closed square) and P. careya (open diamond). Significant regressions (indicated by solid lines) were found for LMA vs rainfall (Erythrophleum chlorostachys), leaf thickness vs rainfall (Erythrophleum chlorostachys, E. tetrodonta and $P$. careya) and leaf density $v s$ rainfall (E. tetrodonta and P. careya).

Fig. 4. Volumetric water content at $0.5 \mathrm{~m}$ depth at the three sites between November 2001 and August 2002, as measured by TDR probes. Probes at Site 2 were burnt by wildfire before the July measurements.

Fig. 5. Differences in quarterly DBH increment at Site 1 (black bars), Site 2 (light grey bars) and Site 3 (dark grey bars) for the four species. Site 2 was burnt in July. Standard error bars are shown.

Fig. 6. A comparison of leaf flush at different sites for the four study species. Periods of major leaf flush are indicated by black fill, minor leaf flush by the stippled areas. Trees at McDonald airstrip were burnt in July. Leaf flush in the evergreen $E$. 
tetrodonta occurred through most of the year at all 3 sites, while in the semideciduous Erythrophleum chlorostachys it was generally confined to a 3-month period. The period of major stem growth for all species is shown by the black bar.

Fig. 7. Mean assimilation per mass $\left(\mathrm{A}_{\text {mass }}\right)$, and per area $\left(\mathrm{A}_{\text {area }}\right)$, stomatal conductance $\left(g_{s}\right)$, saturated water content $\left(\mathrm{H}_{2} \mathrm{O} / \mathrm{DW}\right)$, area per leaf, leaf mass per area (LMA), leaf thickness and leaf density for Buchanania obovata (B. obo), Planchonia careya (P. car), Erythrophleum chlorostachys (Er. chl) and Eucalyptus tetrodonta (E. tet) in the wet season (left hand graphs) and, for Erythrophleum chlorostachys and E. tetrodonta, in the dry season at Site 1 (black bars), Site 2 (light grey bars) and Site 3 (dark grey bars). Standard error bars are shown.

Fig. 8. Mean foliar nitrogen $\left(\mathrm{N}_{\text {mass }}\right)$ and phosphorus $\left(\mathrm{P}_{\text {mass }}\right)$ content for Buchanania obovata (B. obo), Planchonia careya (P. car), Erythrophleum chlorostachys (Er. chl) and Eucalyptus tetrodonta (E. tet) in the wet season at Site 1 (black bars), Site 2 (light grey bars) and Site 3 (dark grey bars). Standard error bars are shown.

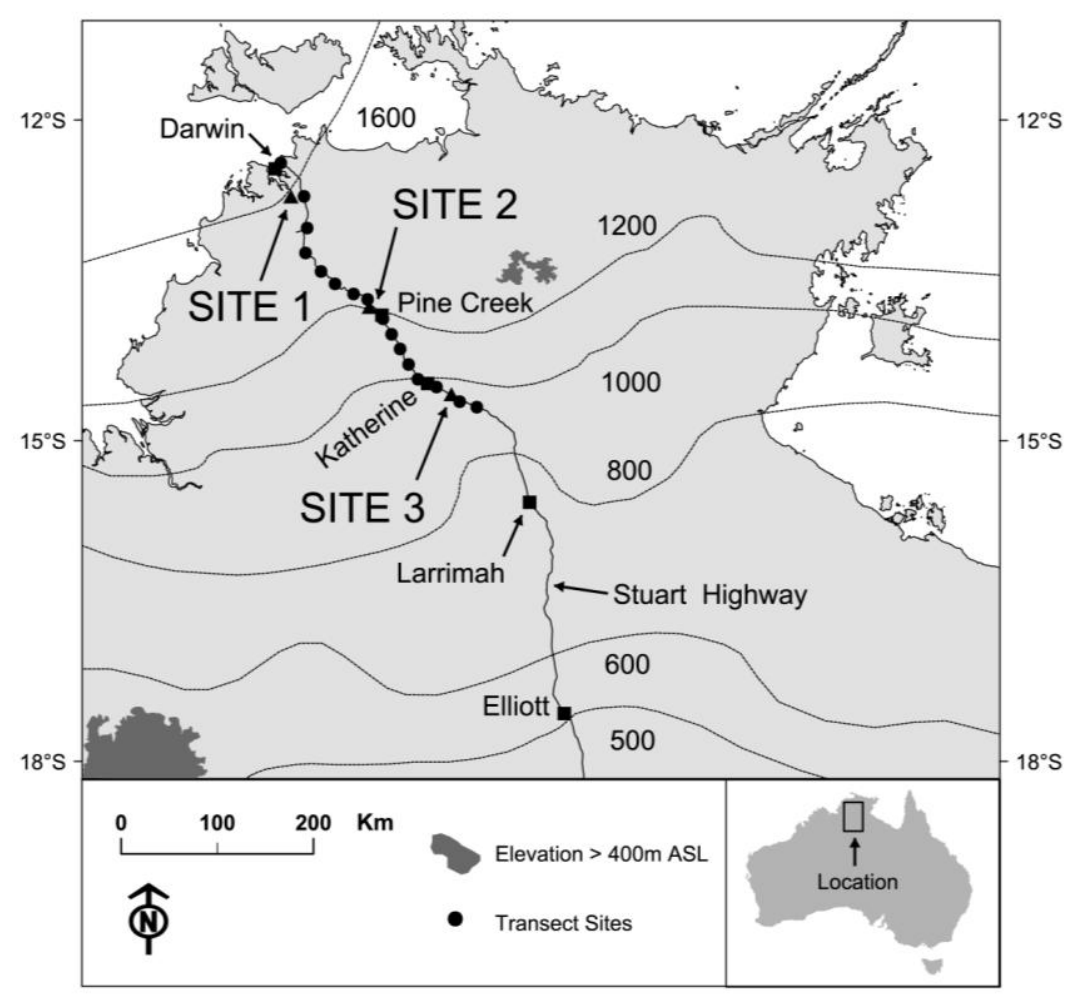



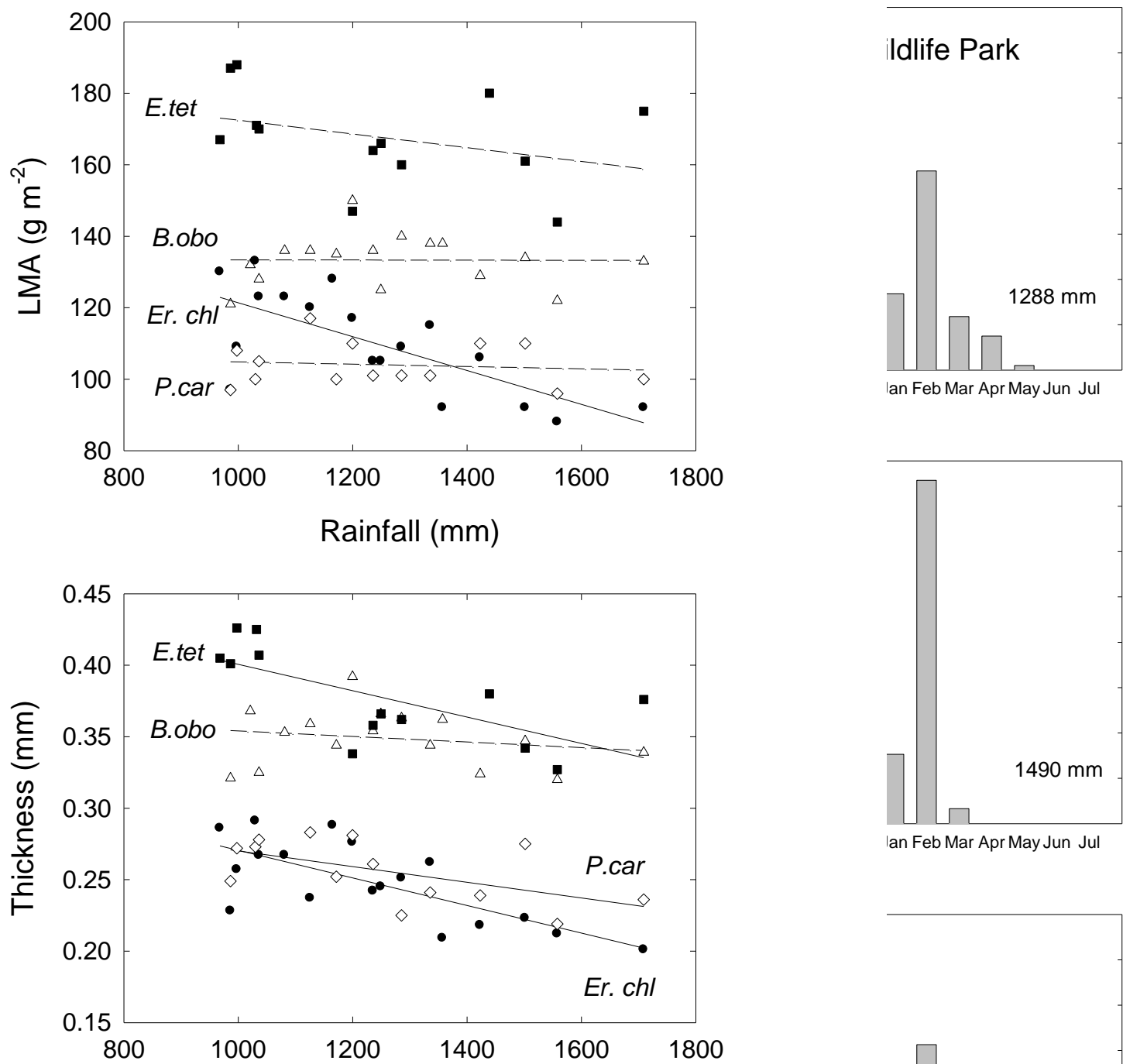

Ian Feb Mar Apr May Jun Jul

Rainfall (mm)
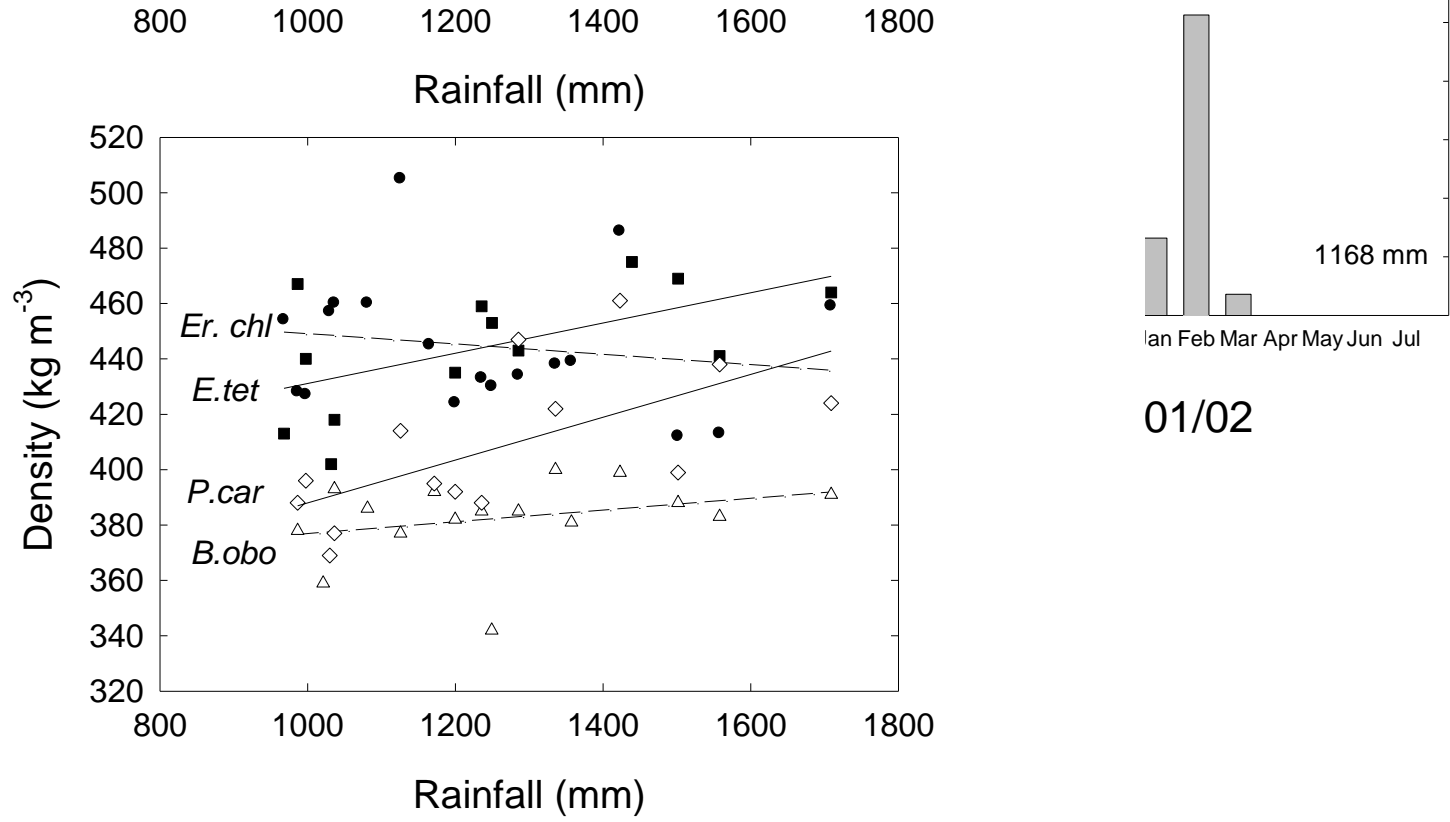

01/02 


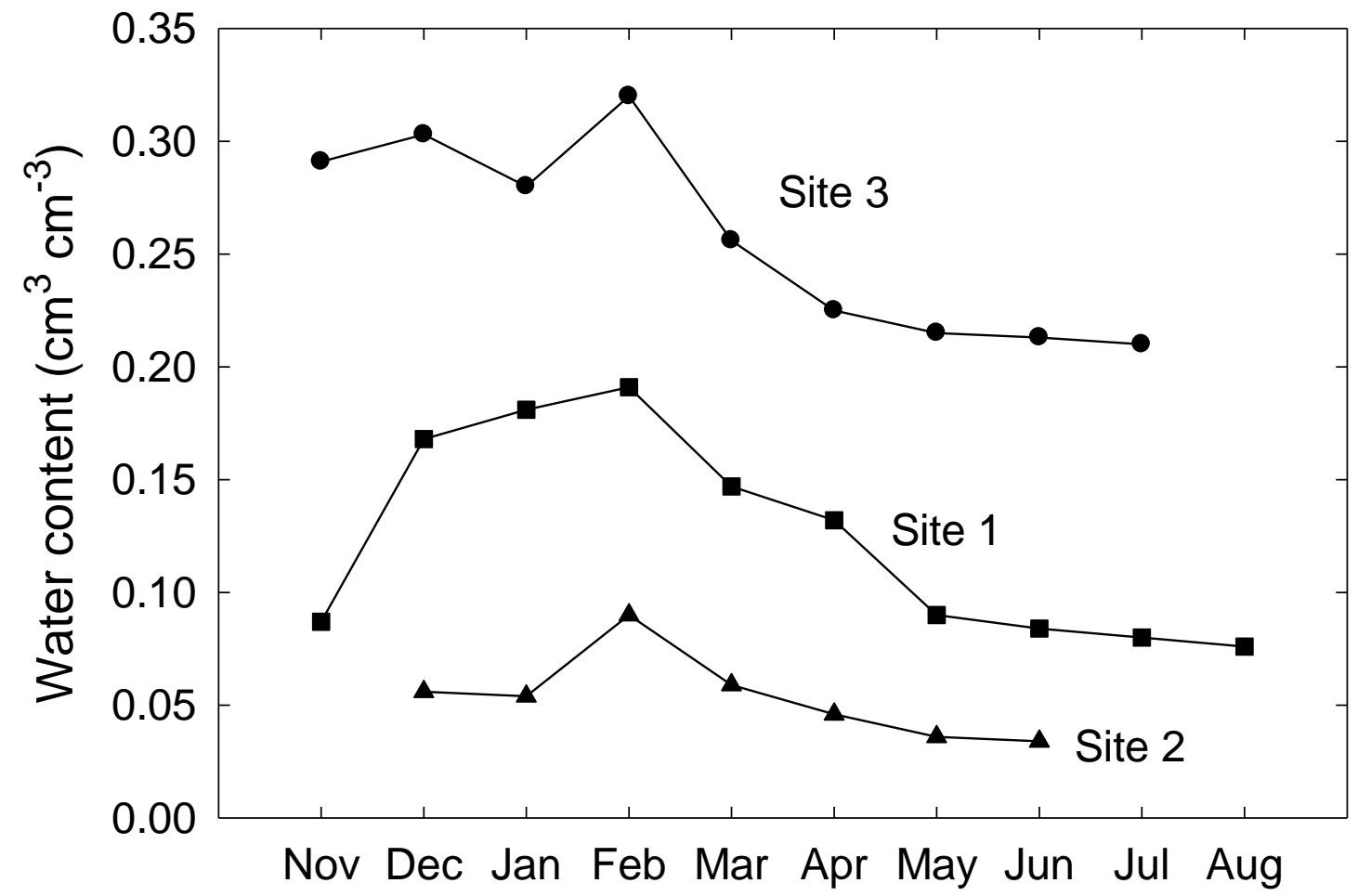




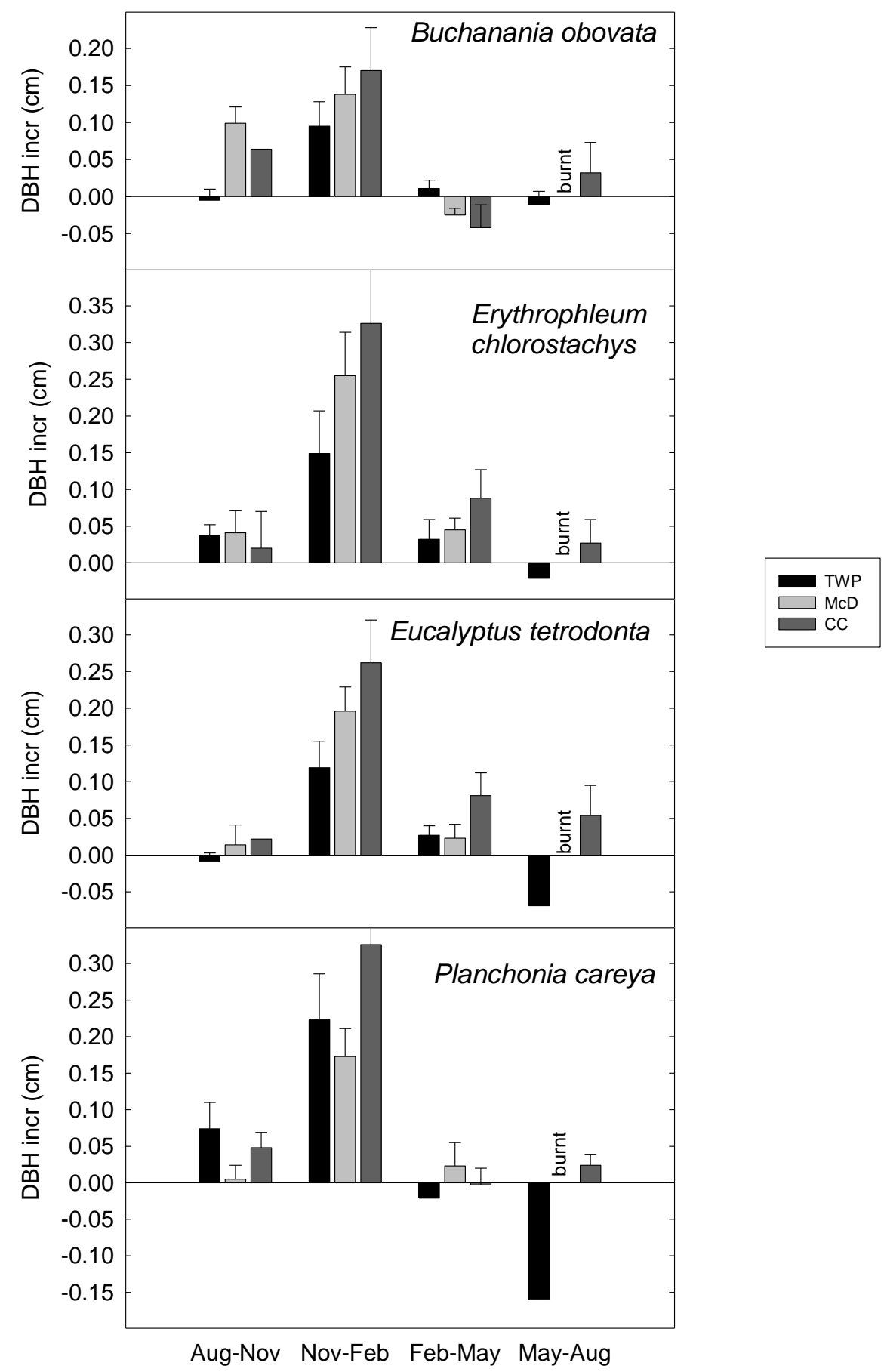




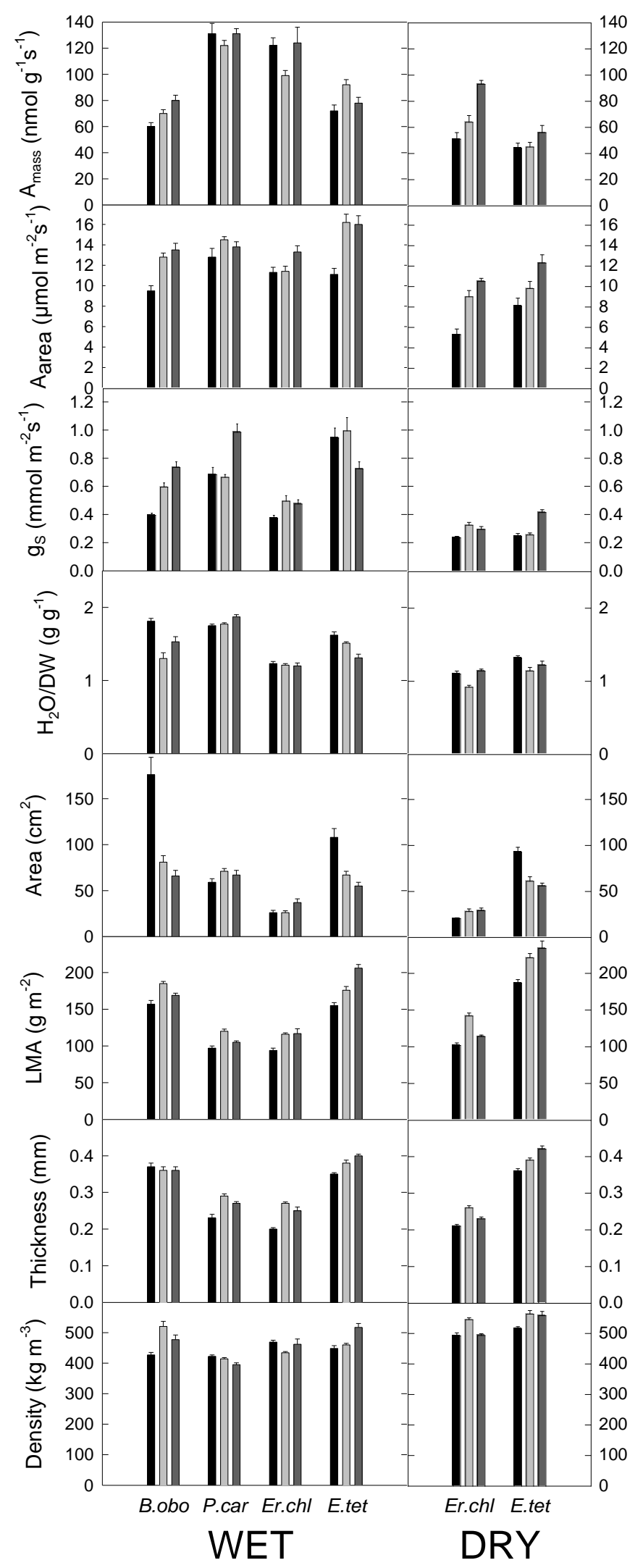



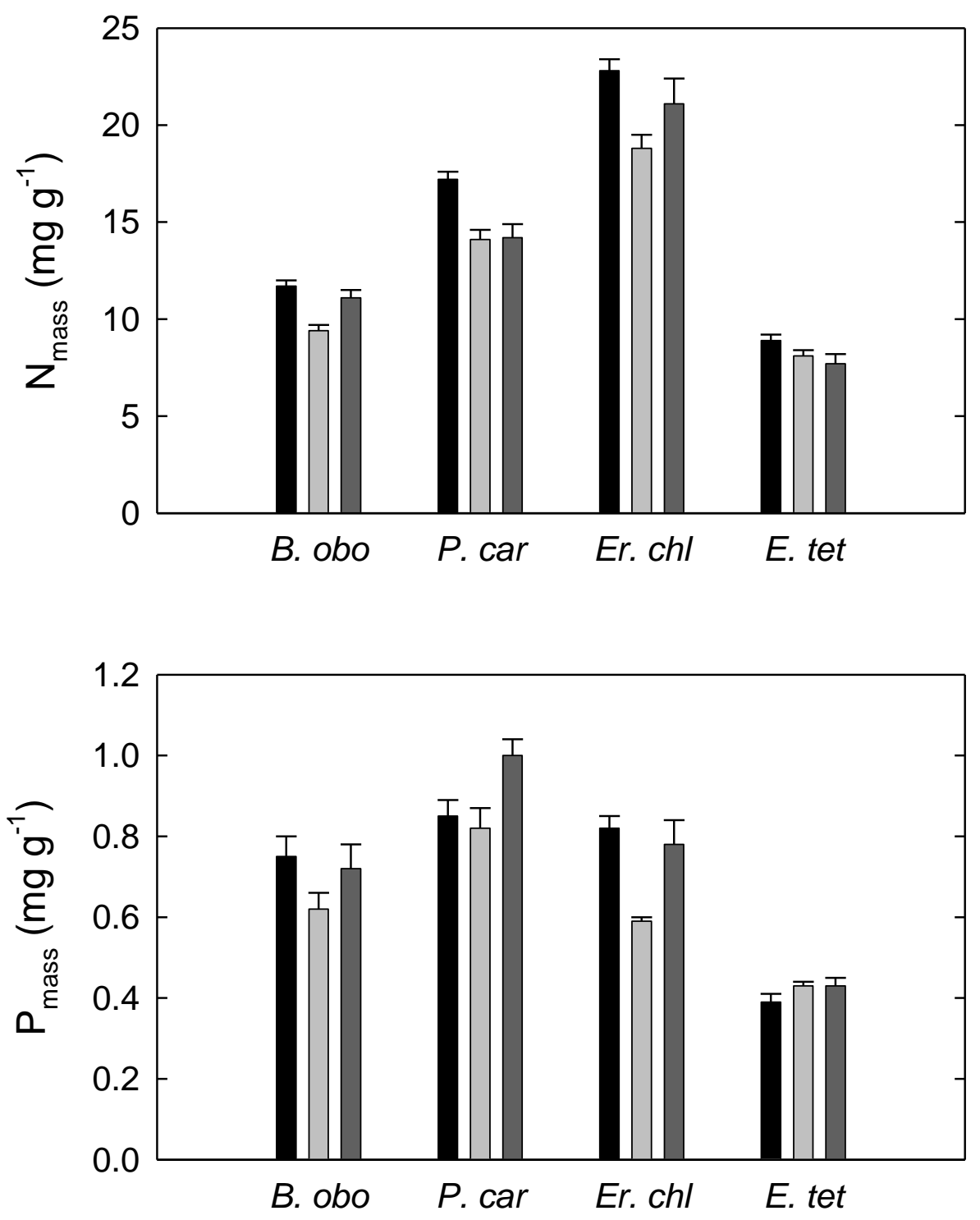

Test 